\title{
Evaluating the economic and nutritional benefits and program challenges of EBT programs at farmers' markets
}

\author{
Kristin Krokowski \\ University of Wisconsin Cooperative Extension Waukesha County
}

\begin{abstract}
Submitted August 22, 2013 / Revised October 29, December 12, and December 16, 2013 /
Accepted December 23, 2013 / Published online March 10, 2014

Citation: Krokowski, K. (2014). Evaluating the economic and nutritional benefits and program challenges of EBT programs at farmers' markets. Journal of Agriculture, Food Systems, and Community Development, 4(2), 37-44. http://dx.doi.org/10.5304/jafscd.2014.042.011
\end{abstract}

Copyright (C) 2014 by New Leaf Associates, Inc.

\begin{abstract}
The number of farmers' markets that offer electronic benefit transfer (EBT) as a method of accepting federally issue Supplemental Nutritional Assistance Program (SNAP) benefits is on the rise, but the long-term success and sustainability of these programs are in question. To evaluate the success and sustainability of farmers' market EBT programs in Wisconsin, 10 farmers' markets participated in a two-year study to determine who benefits from these programs and how best to fund them. This study found that 99 percent of SNAP beneficiaries increased their fruit and vegetable intake by shopping at the farmers' market; however, farmers' market vendors realized little in increased sales. Of the 10 markets involved in the study, nine planned to seek outside funding to continue the program.
\end{abstract}

Kristin Krokowski, University of Wisconsin Cooperative Extension Waukesha County, 515 West Moreland Boulevard AC G22; Waukesha, Wisconsin 53188 USA; +1-262-548-7768; $\underline{\text { Kristin.krokowski@,ces.uwex.edu }}$

\section{Keywords}

electronic benefit transfer, EBT, farmers' market, farmers' market managers, farmers' market vendors, food stamps, sales, Supplemental Nutrition Assistance Program, SNAP

\section{Introduction}

Farmers' markets are an ideal way to mobilize fresh local food. Farmers and other vendors load their products on trucks and bring them to a central location where customers are able to easily access products and vendors are able to easily access customers. Incorporating an Electronic Benefits Transfer (EBT) program into the farmers' market has been identified by many as the next step in serving the community and the market vendors (Jones \& Bhatia, 2011; Larsen \& Gilliland, 2009; Lyson \& Green, 1999).

EBT allows people participating in the Supplemental Nutrition Assistance Program (SNAP), formerly called food stamps, to redeem federal benefits for eligible food items at farmers' markets. 
This access has been tied to increases in fruit and vegetable consumption (Jones \& Bhatia, 2011; Ruelas, Iverson, Kiekel, \& Peters, 2012), an increased customer base for vendors (Fee \& Meléndez, 2012; Montri, Behe, \& Chung, 2013) and retention of federal tax dollars in the local community (Bertmann, Ohri-Vachaspati, Buman, \& Wharton, 2012; Lyson \& Green, 1999; Sadler, Clark, \& Gilliland, 2013). The amount of SNAP benefits issued in Wisconsin has more than tripled since 2007 (Wisconsin Department of Health Services, 2008, 2013), while farmers' market redemption, although growing, has remained low. In 2012 , only US $\$ 170,986$ ( 0.015 percent) of the US $\$ 1,168,136,545$ in benefits issued in Wisconsin were redeemed at farmers' markets (Roper \& Miller, 2013).

Low benefit redemption is just one of the challenges faced by farmers' market EBT programs; the costs of implementing and managing the program must also be considered. Farmers' market EBT programs are expensive (Buttenheim, Havassy, Fang, Glyn, \& Karpyn, 2012; Markowitz, 2010; Wright, Arminio, Reimer, Somers, Darlington, \& Kline, 1998). The typical farmers' market costs include a wireless point-of-service (POS) device, monthly and per-transaction fees, wooden tokens, eight to 10 hours a week of staff time, marketing, and both market and vendor signs. How can farmers' markets, which typically run on shoestring budgets, add EBT processing to the market, and who should be responsible for paying for it? To answer these questions, this study sought to measure the value of farmers' market EBT programs to the market, the farmers ' market vendors, and to SNAP participants with a two-year study of 10 Wisconsin farmers' markets.

\section{Methods}

Potential farmers' market participants were initially identified through GIS maps generated from U.S. Census Bureau data. Maps were generated for Wisconsin counties with the highest SNAP issuance and participation rates based on the Wisconsin Department of Health Services' 2009 data. Once the counties were identified, 1999 census data were used to generate GIS maps. These maps identified the number of individuals below 130 percent of the poverty level by census track. Farmers' markets in each county were identified through two primary sources: the Wisconsin Farmers Market Association list, and the list generated by the Wisconsin Department of Agriculture, Trade and Consumer Protection in collaboration with the University of Wisconsin Cooperative Extension. Markets within or adjacent to the census tracts showing the greatest density of individuals in this category were contacted for participation.

Of the eighteen markets targeted by these initial inquiries, five markets agreed to participate. One of these markets was located in the city of Milwaukee and the other four in large urban areas with populations ranging from 67,000 to 105,000 . Once the targeted markets were in place, an open call went out to farmers' markets around the state to assemble a list of markets interested in participating in the study. Five additional markets were chosen based on a combination of poverty data, the markets infrastructure and the manager or organization's ability to commit to participating in the study for two years. Two of these markets were located in rural areas with a high concentration of SNAP participants but a population of less than twelve thousand residents. All of the participating markets were of similar vendor mix and included a produce, meat, dairy and produce vendors and other additional SNAP qualifying items.

Three of the farmers' markets that agreed to participate in year one did not continue on in the second year due to a failure to implement the study parameters. These markets had a variety of challenges with the program including failing to implement the program, missing reporting deadlines or failing to collect the required data. Replacement farmers' markets were identified from the previously assembled list. These included new markets identified after the beginning of the project, using the same criteria used after for the open call.

Farmers' markets participating in this study were required to be new to farmers' market EBT and were prohibited from accepting credit or debit transactions during the study. No incentive programs were permitted during the project to maintain the consistency of the data across all 10 markets. Each market participating in the study 
received training, information and assistance about starting an EBT program, a wireless POS device for EBT processing, wooden tokens, promotional materials, a $\$ 750$ stipend for staff or program related expenses and ongoing support.

Farmers' markets conducted on site administration of the program which included recruiting and training vendors with SNAP eligible products. Markets were required to offer EBT services and track token purchases and redemption for 17 weeks for the months of July through October of each year. Staff collected surveys and demographic data on participating vendors, tracked token use and redemption and surveyed benefit users. Sales data were analyzed by market event and by individual vendor SNAP sales per market.

SNAP beneficiary surveys were also conducted by the markets during this period. These surveys did not collect any identifying information from participants so that IRB approval was not necessary. Participants were asked if they had shopped at the farmers' market before it offered EBT as a method of payment and if having EBT as a method of payment allowed them to eat more fruits and vegetables.

Each farmers' market administered its EBT program in a similar way. Markets assigned a location for the wireless POS device, either as a standalone booth or as part of the markets information table. SNAP participants brought their benefits card to that location to exchange their benefits for wooded tokens. The wooden tokens were then spent with participating vendors with SNAP eligible products. The vendors redeemed the tokens with the market. The frequency of token redemption for vendors varied by market. The larger markets with higher token volumes redeemed tokens each market day. One market, with a low token volume redeemed tokens only twice a season. Vendors were paid for tokens either with cash or by check on site or the next market day depending on the markets policy.

At the conclusion of the study, follow-up evaluations were conducted with the participating farmers' market vendors and market staff involved in the program to determine their perceptions of the farmers' market EBT program and its value. The University of Wisconsin River Falls Survey
Research Center obtained IRB human subjects approval and collected the follow-up survey data to prevent bias and allow participants to answer the survey questions honestly. Farmers' market managers were interviewed by phone. Farmers' market vendor surveys were administered by email for those vendors who provided an email address. The remaining vendors were surveyed by mail. Farmers participating in multiple farmers' markets in the study were asked to fill out a separate survey for each market. Responses were then aggregated by market for analysis.

\section{Results}

Seven of the 10 farmers' markets originally identified were successful at starting up an EBT program and maintaining it for two complete seasons. The total EBT redemption at the seven markets for 2011 was US $\$ 15,571$ with the redemption at individual markets ranging from US $\$ 537$ to US $\$ 4,381$. All of the markets saw an increase in sales in year 2 of the program. Total sales using EBT in 2012 for all seven markets was US $\$ 34,863$, an increase of 224 percent over the previous year. Individual markets ranged from US\$634 to US\$7,384, with individual market increases of 15-277 percent (figure 1).

Annual SNAP sales of participating vendors with eligible products varied greatly for each of the six markets that provided vendor-level data. In 2011 redemptions per vendor ranged from US $\$ 0$ to US\$624. In 2012 redemptions per vendor increased to a range of US $\$ 0$ to US\$999. Participating vendors selling fruits and vegetables were the primary recipients of SNAP benefits, followed by meat, bakery, and dairy vendors. However, because individual program vendors sold multiple types of products there are no totals for individual item categories. Five of the six markets had an increase in the maximum redeemed amount for an individual vendor in 2012, although many of the vendors redeemed no EBT benefits (figure 2). Individual vendor totals are based on individual markets. The average weekly sales increased at all seven markets from 2011 to 2012. In the first year the average weekly sales for individual markets ranged from US\$31.59 to US\$257.71. In the second year, EBT sales increased from a range of US $\$ 37.29$ to 
US $\$ 434.35$ (figure 3). Average individual vendor sales by week ranged from US $\$ 0.91$ to US\$8.89 in 2011 and US\$1.86 to US\$13.99 in 2012.

The number of participating vendors increased for all markets during the study. The comparison was made between the numbers of participating vendors at each market in the beginning of the program and at the end of the second year. The combined vendor participation for all markets increased 19 percent during the course of the study. Individual market vendor participation increased in a range between 0 and 43 percent.

\section{In 2011, 607 SNAP} participants were surveyed about the impact of adding EBT services to the farmers' market at the time of benefit redemption. Of those surveyed, 87 percent indicated that their fruit and vegetable consumption increased with the addition of EBT as a payment option. In 2012, 99 percent of the 1,320 individuals surveyed likewise agreed that their fruit and vegetable consumption increased. Market staff also asked SNAP participants if they had shopped at the farmers' market before it offered EBT services. In both 2011 and 2012, 75 percent of the SNAP participants indicated they had shopped at the market before it offered EBT.

Farmers' market vendors were surveyed about their experience with EBT at each individual market at which they participated in the EBT program. The survey took place in March 2013 following the conclusion of the study in 2012. Overall, 264 vendors received the survey either by mail or online. Surveys were completed by 85 vendors with a total by Market (US\$)
Figure 1. Annual EBT Farmers' Market Vendor Sales by Market for 2011 and 2012 by Market (US\$)

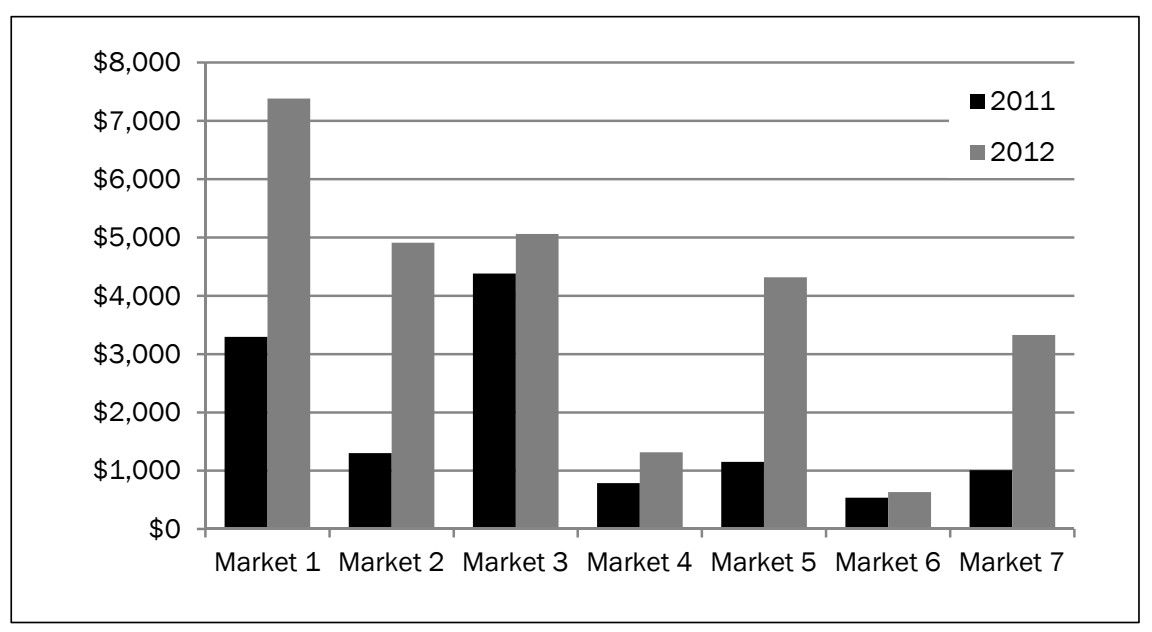

Figure 2. Maximum Annual Redemption per Vendor for 2011 and 2012

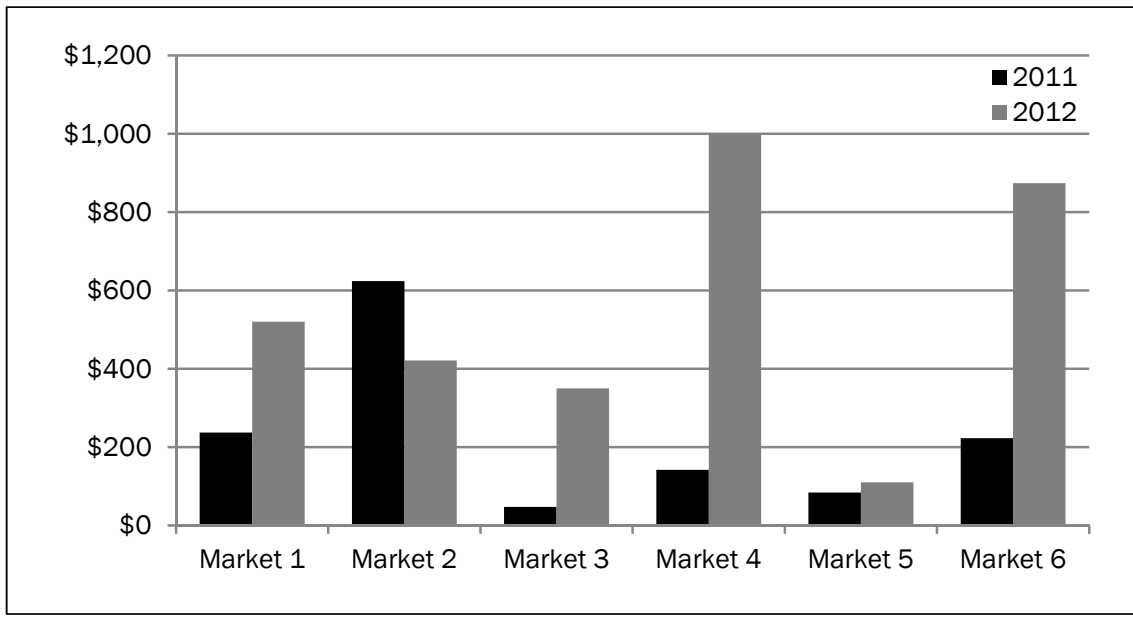

of 104 responses. Seventeen vendors had multiple responses for participating in more than one market. Vendors participating in the EBT program were asked if they felt the program was successful. Twenty-nine percent of vendors agreed or strongly agreed. Fifty-one percent either disagreed or strongly disagreed. The remaining twenty percent of vendors neither agreed nor disagreed.

When asked what part of the program was most successful, vendors overwhelmingly indicated the ease of the token system and the ability to provide fresh local food to SNAP participants. The perceived challenges of the program included a lack of promotion and an inability to swipe the 
Figure 3. Average Weekly EBT Sales for 2011 and 2012 by Market (US\$)

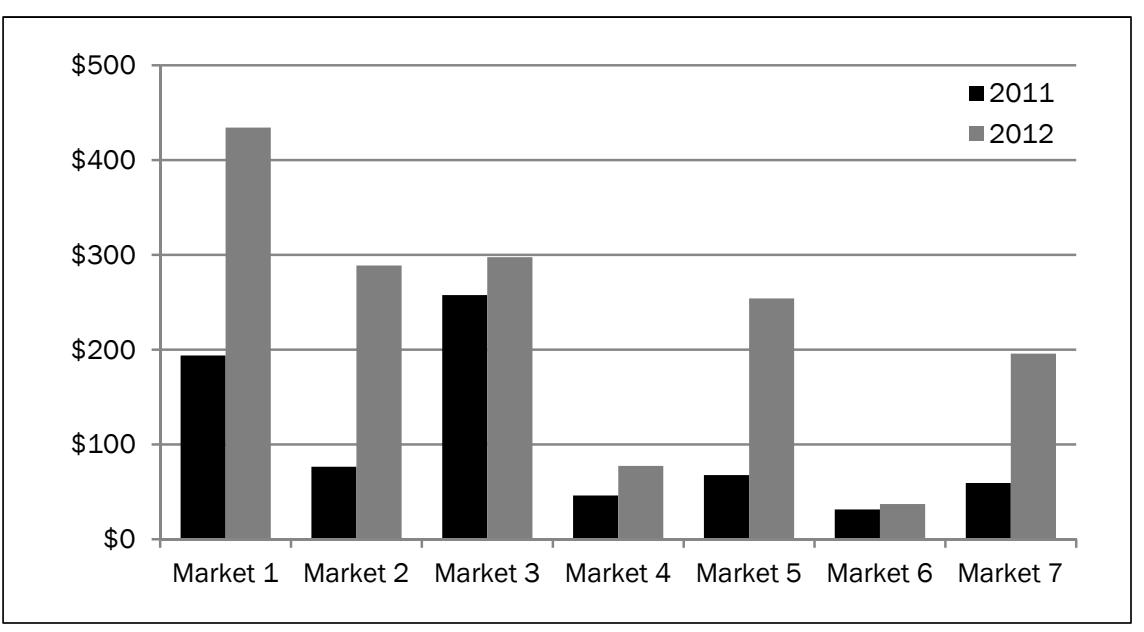

Discussion

The farmers' market vendors and managers in this study support incorporating EBT processing into the market. Even those vendors who expressed that they were not supportive of governmentissued food benefits in the comments section of our survey found them more acceptable if they were being spent at the farmers' market with local farmers. These responses are similar to those found in other studies

benefit card for customers at their stalls.

Although 93 percent of the surveyed vendors were supportive of continuing the EBT program at the market, only 13 percent would be willing to pay a fee to participate. Of those willing to pay a fee, 79 percent were willing to pay up to US $\$ 15$, and 21 percent would pay US $\$ 16-U S \$ 25$. No vendor was willing to pay a fee higher than US $\$ 25$ to participate in the program. Reasons for being unwilling to pay a fee included the low profitability of the program, the extra effort for the vendor to accept EBT tokens and exchange them with the market, and the belief that vendors already pay enough in vendor fees.

Farmers' market managers who participated in the study during the 2012 market season were contacted in January of 2013 for a telephone survey regarding the program. Eight of the ten market managers participated in the survey.

All of the managers participating in the survey either agreed or strongly agreed that the EBT program was a success at their market. Nearly all indicated that the most successful aspect was the benefit to the SNAP clients. Their reasons included the appreciation of SNAP participants for the service and the repeat visits to the market by this group. Manager challenges focused primarily on the administration of the program. Dispersing tokens and reimbursing farmers required significant time and effort on the part of the market staff. Challenges also included language barriers and difficulties attracting SNAP benefit recipients. measuring the impact of incorporating EBT into farmers' markets (Buttenheim et al., 2012; Cole, McNees, Kinney, Fisher, \& Krieger, 2013). These studies also reinforce the concept that while market managers and the majority of vendors are philosophically supportive of the program, their support diminishes when the program costs are no longer subsidized.

In addition to the cost of the wireless devices and program fees, many markets, even those run by established organizations and municipalities, simply lack the capacity and infrastructure to administer the program. The additional accounting duties and legal responsibilities of the program are perceived as a barrier to many markets (Cole et al., 2013). Managers' responses in the survey affirmed the labor-intensive nature of the program. Many of their challenges related to the staff time needed to staff a booth at the market and to redeem the tokens with vendors. The eight to 10 hours a week of additional staff time for EBT administration did not allow time for many of the best practices recommended for farmers' markets EBT programs, including onsite community events and reaching out to organizations serving SNAP participants (Owens \& Verel, 2010). Increasing the engagement of SNAP participants through incentive programs and education may increase sales and create greater justification for farmers' markets to run EBT programs (Baronberg, Dunn, Nonas, Dannefer, \& Sacks, 2013; Fee \& Meléndez, 2012).

In addition to the administrative challenges of 
operating an EBT program, markets must also measure the program's success. Market managers, vendors, and SNAP participants define success very differently. In the follow-up surveys, all of the farmers' market managers agreed or strongly agreed that the EBT program was a success at the market, while only 29 percent of vendors thought it was successful. The managers based their definition of success on the comments of the SNAP participants, while the vendors based it on the financial return. Managers must also think of how potential funders for the program will define success. EBT programs must be valued by all of the stakeholders to attain positive effects over the long term.

Vendor surveys combined with sales data indicate that success for vendors is related to an increase in sales. Although SNAP redemption increased 224 percent in year two over year one, the most any single vendor benefited was US $\$ 999$ in gross revenue. The farmer must still deduct the costs of production, marketing, and labor, leaving significantly less net additional income for the farmer.

It also takes vendors more effort to conduct an EBT transaction than a cash transaction (Cole et al., 2013). Vendors must keep track of tokens, count them, and redeem them with the market office. Some vendors must wait weeks to redeem their tokens and receive a check for their value. This system is a great deal more complicated than the simple process of exchanging their products directly with a customer for cash.

Who should cover the cost of the program? The managers of farmers' markets that indicated they would continue the program after the study ended said they would seek outside forms of support for the program, including sponsorships, partnerships, grants, and contributions. This adds yet another layer to the complexity of hosting an EBT program to already overextended market managers. Once a program supporter has been identified, managers may be expected to continually collect data and report back to the funding organization. Many farmers' markets in Wisconsin do not have not-for-profit status and cannot accept tax-deductible contributions.

Nevertheless, for farmers' markets unable or unwilling to take on these responsibilities, other opportunities still exist. In our study, two of the farmers' markets participating had their EBT programs run separately from the market by an outside group. In addition to finding outside sources of revenue to support the program or externalizing the program, markets can also look for ways to reduce costs. The cost of a wireless POS unit is a significant barrier for many markets wishing to start an EBT program (Buttenheim et al., 2012; Cole et al., 2013). These units are not required for all markets. Although they are low-tech, paper vouchers can still be used for SNAP sales at a farmers' market. Authorized markets simply call in with the appropriate information, including the transaction amount. Once the transaction is complete the SNAP participant signs the voucher and both parties get a copy. This method is practical and economical for markets with low redemption volume that wish to improve food access.

Evolving software technology piloted by developer Novo Dia Group may also improve the access of vendors. This software currently enables participating vendors at Michigan farmers' markets to accept several types of benefits cards, including SNAP, Women, Infants and Children Electronic Benefits Transfer Cash Value Benefits (WIC EBT CVB), Farmers Market Nutrition Program (FMNP), and Summer EBT for Children (SEBTC). Additionally, vendors can process debit and credit card transactions with the same device, providing even more sales opportunities with no extra hardware investment (Wiles, 2012). Smartphone apps that process EBT transactions are rapidly developing and may soon make accepting EBT on the vendor level more affordable. Enabling widespread use of EBT technology by market vendors would remove the additional costs incurred by a marketrun program, including staff time and tokens. Vendor-level transactions have also been linked to increased overall SNAP redemption at farmers' markets when compared to market-run programs (Buttenheim et al., 2012).

Even more important and more impactful than finding sponsors and reducing costs is increasing the volume of SNAP traffic at farmers' markets. Wisconsin farmers' markets redeemed just .015 percent of the EBT benefits issued in the state in 
2012. Michigan, the leader in redemption in the Midwest, redeemed 0.05 percent of benefits issues in that state (Roper \& Miller, 2013). What kind of impact on nutrition and local economies could be realized if just one percent of the US $\$ 74$ billion in SNAP benefits issued in 2012 were spent on local agricultural products at farmers' markets? How many more farmers' markets could thrive in neighborhoods with high densities of SNAP participants?

\section{Conclusions}

Increasing access to fresh fruits, vegetables, and other locally produced SNAP-eligible items is not a simple process. SNAP participants are able to eat more fruits and vegetables when local farmers markets' accept EBT, but this increased access has not translated into meaningful economic impact for farmers' markets vendors in Wisconsin.

The answer to increasing the efficiency of this program may be to transition it to the vendors. If vendors were to adopt smart-device technology and offer EBT services at the point of sale, it would eliminate many of the program's costs and complexities. For vendors to justify the expense of adopting this technology and paying for its use, however, accepting SNAP benefits must be profitable. More research is needed on ways to substantially increase SNAP sales at farmers' markets or reduce the cost to vendors in order to create a sustainable system that benefits farmers' markets, vendors, and SNAP participants.

\section{Acknowledgments}

This study was funded by the United States Department of Agricultures' Farmers' Market Promotion Program.

\section{References}

Baronberg, S., Dunn, L., Nonas, C., Dannefer, R., \& Sacks, R. (2013). The impact of New York City's Health Bucks Program on electronic benefit transfer spending at farmers markets, 2006-2009. Preventing Chronic Disease, 10, 130113. http://dx.doi.org/10.5888/pcd10.130113

Bertmann, F. M. W., Ohri-Vachaspati, P., Buman, M. P., \& Wharton, C. M. (2012). Implementation of wireless terminals at farmers' markets: Impact on
SNAP redemption and overall sales. American Journal of Public Health. 102(7), e53-e55. http://dx.doi.org/10.2105/AJPH.2012.300727

Buttenheim, A. M, Havassy, J., Fang, M., Glyn, J., \& Karpyn, K. (2012). Increasing Supplemental Nutrition Assistance Program/electronic benefits transfer sales at farmers' markets with vendoroperated wireless point-of-sale terminals. Journal of the Academy of Nutrition and Dietetics, 112(5), 636-641. http://dx.doi.org/10.1016/j.jand.2011.12.021

Cole, K., McNees, M., Kinney, K., Fisher, K., \& Krieger, J. W. (2013). Increasing access to farmers markets for beneficiaries of nutrition assistance: Evaluation of the Farmers Market Access Project. Preventing Chronic Disease, 10, 130121. http://dx.doi.org/10.5888/pcd10.130121

Fee, R., \& Meléndez, M. L. (2012). 2011 electronic benefit transfer and Farmers Market Initiative evaluation report (Report No. C2226RO1). Retrieved from the Blue Cross and Blue Shield of Minnesota website: http://www.preventionminn esota.com/objects/pdfs/2011EBT_FarmersMarket EvaluationReport.pdf

Jones, P., \& Bhatia, R. (2011). Supporting equitable food systems through food assistance at farmers' markets. American Journal of Public Health, 101(5), 781-783. http://dx.doi.org/10.2105/AJPH.2010.300021

Larsen, K., \& Gilliland, J. (2009). A farmers' market in a food desert: Evaluating impacts on the price and availability of healthy food. Health and Place, 15(4), 1158-1162. http://dx.doi.org/10.1016/ j.healthplace.2009.06.007

Lyson, T. A., \& Green, J. (1999). The agricultural marketscape: A framework for sustaining agriculture and communities in the northeast. Journal of Sustainable Agriculture, 15(2-3), 133-150. http://dx.doi.org/10.1300/J064v15n02 12

Markowitz, L. (2010). Expanding access and alternatives: Building farmers' markets in low-income communities. Food and Foodways, 18(1-2), 66-80. http://dx.doi.org/10.1080/07409711003708512

Montri, D. N., Behe, B. K., \& Chung, K. (2013). Using a case approach to assess farmers' attitudes regarding central terminal model electronic benefits transfer (EBT) programs at select Michigan farmers markets. Hort Technology, 23(1), 38-43. http://horttech.ashspublications.org/ 
Owens, N., \& Verel, K. (2010). SNAP/EBT at your farmers market: Seven steps to success. Project for Public Spaces, Inc., and Wholesome Wave. Retrieved from the Project for Public Spaces website: http://www.pps.org/store/books/ snapebt-atyour-farmers-market-seven-steps-to-success/

Roper, N., \& Miller, S. (2013, February 15). Slow and steady: Farmers market SNAP sales continue to expand [Online news item]. Retrieved from http:// farmersmarketcoalition.org/snap-sales-upin-2012

Ruelas, V., Iverson, E., Kiekel, P., \& Peters, A. (2012). The role of farmers' markets in two low income, urban communities. Journal of Community Health, 37(3), 554-562. http://dx.doi.org/10.1007/s10900011-9479-y

Sadler, R. C., Clark, M. A. R., \& Gilliland, J. A. (2013). An economic impact comparative analysis of farmers' markets in Michigan and Ontario. Journal of Agriculture, Food Systems, and Community Development, 3(3), 61-81. http://dx.doi.org/10.5304/jafscd.2013.033.009

Wiles, J. (2012, June 26). Mobile payment solution from Novo Dia Group enables Michigan farmers markets to tap into the SNAP and WIC market
[Press release]. Retrieved from http://www.novodiagroup.com/mobile-paymentsolution-from-novo-dia-group-enables-michiganfarmers-markets-to-tap-into-the-snap-and-wicmarket/

Wisconsin Department of Health Services. (2008). Eligibility management (income maintenance) - FoodShare Wisconsin data. FoodShare benefits payments by calendar year: 2007 [Data set]. Retrieved from http://www.dhs.wisconsin.gov/em/rsdata/

Wisconsin Department of Health Services. (2013). Eligibility management (income maintenance) — FoodShare Wisconsin data. FoodShare benefits payments by calendar year: 2012 [Data set]. Retrieved from http://www. dhs.wisconsin.gov/em/rsdata/index.htm

Wright, W. P., Arminio, M., Reimer, P., Somers, C., Darlington, J., \& Kline, K. (1998). Technical and cost feasibility of EBT equipage in farmers' markets and mobile food retailers: Final feasibility report. Alexandria, Virginia: U.S. Department of Agriculture Food and Nutrition Service, Office of Analysis and Evaluation. Retrieved from http://www.fns.usda.gov/technical-and-costfeasibility-ebt-equipage-farmers $\% \mathrm{E} 2 \% 80 \% 09$ markets-and-mobile-food-retailers 